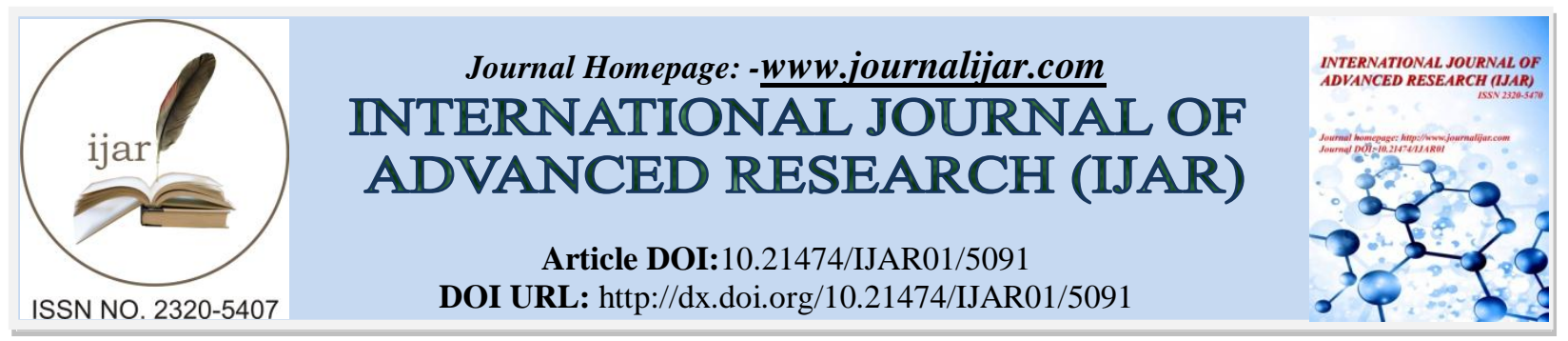

RESEARCH ARTICLE

\title{
A PROSPECTIVE STUDY OF OUTCOME OF SEPTOPLASTY IN ALLERGIC RHINITIS IN TERTIARY HOSPITAL.
}

Dhinakaran Natarajan, Saravanamuthu Subbiah and Raghuram Nataraj.

\section{Manuscript Info}

Abstract

Manuscript History

Received: 07 June 2017

Final Accepted: 09 July 2017

Published: August 2017

Copy Right, IJAR, 2017,. All rights reserved.

\section{Introduction:-}

Difficulty in nasal breathing is probably the most common complaint in rhinological practice. Among the major causes are Deviated nasal septum (DNS) and Allergic rhinitis (AR). Treatment of symptomatic DNS is surgical with high success rate, in terms of patient satisfaction, particularly if the deformity is localised in the caudal septal end or the valve area ${ }^{[1]}$. Treatment of AR is a much complex issue, including medication, avoidance of causative allergen, desensitisation and the use of a variety of surgical techniques, which mainly aim at the reduction of the size of the inferior turbinates ${ }^{[2]}$.

When deciding on the best therapeutic strategy for patients with nasal pathology one must have a tool for the assessment of subjective symptoms. The Nasal Obstruction Symptom Evaluation(NOSE) Scale is a disease -specific quality of life instrument used for use in nasal obstruction, developed by Stewart et $a l^{[3]}$.

The co-existence of DNS and AR often present a therapeutic challenge for the physician. The aim of this study is to assess the outcome of septoplasty using self- assessment scale and to examine the extent to which this outcome is affected by allergic rhinitis status ${ }^{[4,5,6]}$.

\section{Materials And Methods:-}

\section{Subjects:-}

The study was conducted in a tertiary referral center - department of otorhinolaryngology, Government Rajaji Hospital, Madurai, between June 2015 and February 2017. It was approved by the Institute ethics committee. Ninety eight patients underwent septoplasty during the one year study period. Follow up data were obtained from Eighty three patients. Fifteen patients either failed to return for follow up or presented with post-operative complications. Therefore complete data were available for 83 subjects. Of the 83 patients in the study, 20 were allergic patients and 63 were non - allergic. Patients with Nasal septal deviation were chosen based on their complaint about difficulty in nasal breathing and diagnosis of Deviated nasal septum (DNS) was made solely on the anterior rhinoscopic findings. Clinical diagnosis of Allergic Rhinitis(AR) was based on standard criteria ${ }^{[7]}$ prescribed by Allergic Rhinitis and its Impact on Asthma(ARIA) 2007 guidelines. AR subjects were included regardless of recent local medication use, but patients receiving systemic steroids were excluded from the study. Patients undergoing other simultaneous surgical procedures, such as rhinoplasty were 
excluded. All subjects were interviewed the day before surgery, and an informed consent was obtained. Septoplasty was performed under local or general anaesthesia by the team members of Prof.Dr. N. Dhinakaran.

Self- assessment measure:- NOSE scale

During interview, demographic data were recorded and patients were asked to complete the Nasal Obstruction Symptom Evaluation (NOSE) scale (table 1), which is a validated, disease-specific quality of life instrument for use in nasal obstruction ${ }^{[8]}$. According to this scale, patients were asked to evaluate the severity of their nasal congestion, their difficulty in nasal breathing, their difficulty in breathing during their sleep and their difficulty in breathing overall. The severity of their symptoms was recorded based on a sale from 0 to 4,0 standing for absence of the symptom and 4 for severe problem. Possible scores ranged from 0 to 20 and higher scores implied a greater subjective degree of obstruction (5 questions, each rated on a 5-point Likert scale). Patients completed the NOSE questionnaire on the day before and approximately 4 weeks after the septoplasty procedure.

\begin{tabular}{|c|c|c|c|c|c|}
\hline ID\# & & & \multicolumn{3}{|c|}{ Date } \\
\hline \multicolumn{6}{|c|}{ Nasal Obstructive Symptoms Evaluation Scale } \\
\hline \multicolumn{6}{|c|}{$\begin{array}{l}\rightarrow \text { To the Patient: Please help us to better understand the impact of nasal obstruction } \\
\text { on your quality of life by completing the following survey. } \\
\text { Thank you! }\end{array}$} \\
\hline \multirow{2}{*}{\multicolumn{6}{|c|}{$\begin{array}{l}\text { Over the past } 1 \text { month, how much of a problem were the following conditions for you? } \\
\text { Please Circle the Most Correct Response }\end{array}$}} \\
\hline & & & & & \\
\hline & $\begin{array}{l}\text { Not a } \\
\text { Problem }\end{array}$ & $\begin{array}{l}\text { Very Mild } \\
\text { Problem }\end{array}$ & $\begin{array}{l}\text { Moderate } \\
\text { Problem }\end{array}$ & $\begin{array}{l}\text { Fairly Bad } \\
\text { Problem }\end{array}$ & $\begin{array}{l}\text { Severe } \\
\text { Problem }\end{array}$ \\
\hline 1. Nasal congestion or stuffiness & 0 & 1 & 2 & 3 & 4 \\
\hline 2. Nasal blockage or obstruction & 0 & 1 & 2 & 3 & 4 \\
\hline $\begin{array}{l}\text { 3. Trouble breathing through my } \\
\text { nose }\end{array}$ & 0 & 1 & 2 & 3 & 4 \\
\hline 4. Trouble sleeping & 0 & 1 & 2 & 3 & 4 \\
\hline $\begin{array}{l}\text { 5. Unable to get enough air } \\
\text { through my nose during } \\
\text { exercise or exertion }\end{array}$ & 0 & 1 & 2 & 3 & 4 \\
\hline \multicolumn{6}{|c|}{$\begin{array}{l}\text { 6. Please mark on this line how troublesome is your difficulty in breathing through } \\
\text { your nose: }\end{array}$} \\
\hline None & Mec & dium & & & Severe \\
\hline
\end{tabular}

\section{Rhinoscopy and endoscopy:-}

All patients underwent anterior rhinoscopy and nasal endoscopy using a zero degree Hopkins rigid endoscope for a more detailed description of the nasal anatomy. Recorded data included the side of maximum deviation(right/left), thesite of maximum deviation based on the five area division by Cottle ${ }^{[9]}$, status of nasal mucousa (normal/ pale/ congested), inferior turbinate hypertrophy (absent/ right/ left/ bilateral), symptoms of headache, post nasal drip, nasal bleed, smell disturbance. Serum total IgEmeasurements ${ }^{[10]}$ was made in all subjects pre operatively.

The septoplasty procedure ahemitarnsfixion incision was performed, subperichondrial and subperiosteal tunnels were developed as required and deviated cartilage, bone were resected with continuity of the dorsal and caudal parts of septal cartilage. Any bony crests found were resected. A tamponade was placed and removed on first or second post operative day. During this period intravenous antibiotics were administered. All patients received standard post operative care with frequent saline nasal douches and administration of xylometazoline nasal drops and were subjected to nasendoscopy assisted cleaning every week for four consecutive weeks post operatively. NOSE questionnaire was conducted at about four weeks post operatively. Patients with post opearative complications, such as haematoma or synachiae, were excluded from the study.

Statistical analysis. 
Univariate comparisons of pre-operative patient characteristics were made between patients with and without allergic rhinitis. Continuous variables were compared using the independent samples t-test and other tests( Pearson's chi square test, Fisher's exact test, etc.) as appropriate. Possible differences in the degree of Septal deviation between the two groups were assessed using the chi-squared test for trend. Methods appropriate for paired data such as paired samples t-test were applied to assess the degree of change in NOSE scores after Septoplasty, both overall and according to allergic rhinitis status. IBM SPSS STATISTICS 20 software was used to analyse the data and $\mathrm{p}$ value $<0.05$ was considered statistically significant.

\section{Results:-}

Ninety eight patients underwent septoplasty during the one year study period. Follow up data were obtained from Eighty three patients. Fifteen patients either failed to return for follow up or presented with post-operative complications. Therefore, complete data were available for 83 subjects. Of the 83 patients in the study, 20 were allergic patients and 63 were non-allergic. Allergic and non-allergic groups were not found to differ at baseline to a statistically significant extent with regard to gender, side of maximal deviation (left/right), or degree of nasal septal deviation. In addition, the pre-operative NOSE score (mean 16.55 SD 1.820 for allergic group, mean $14.79 \pm \mathrm{SD} 2.719$ for non-allergic group, $\mathrm{p}=0.375$ ) did not differ significantly between groups (fig 1)

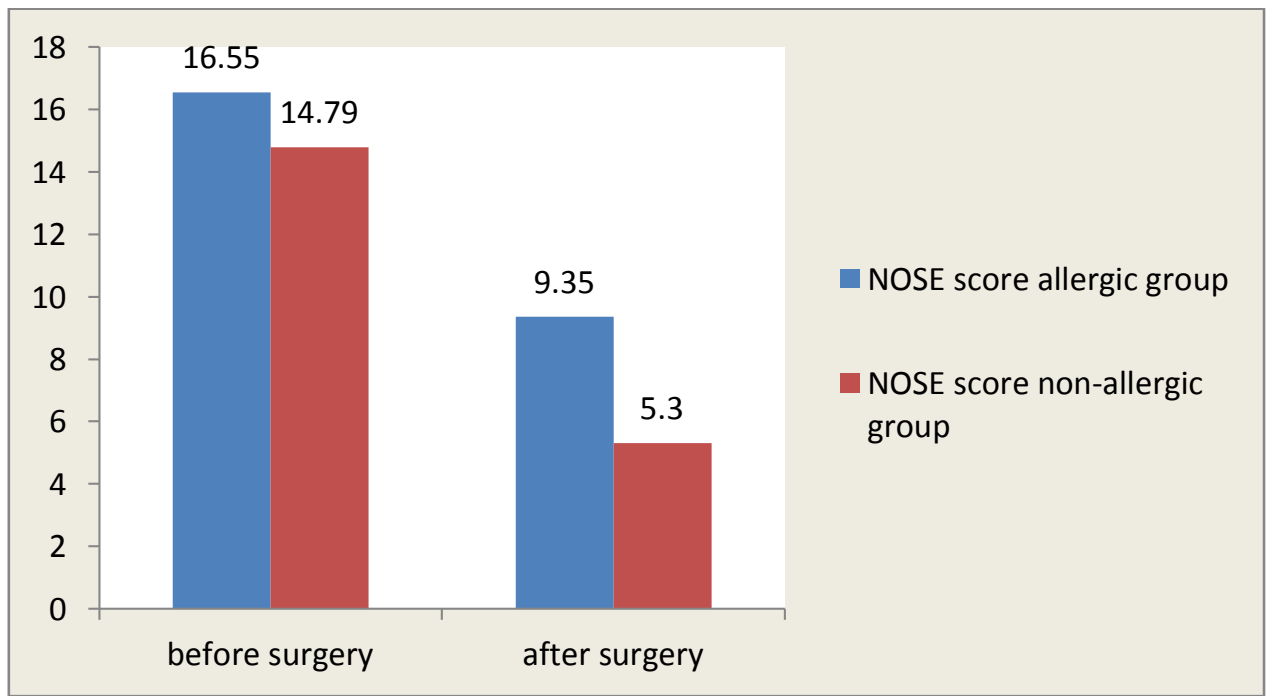

Fig 1:- NOSE score before and after surgery.

Follow-up was performed approximately a month after the procedure and consisted of the same testing as pre -operatively. Following Septoplasty, a general decrease in NOSE scores was observed (fig.2). Only one patient had an increased NOSE score after septoplasty. There was extremely strong evidence that the average decrease was greater in patients who did not have allergic rhinitis (mean decrease $9.49 \pm \mathrm{SD} 4.004$ ) when compared to the allergic group (mean decrease $7.20 \pm \mathrm{SD} 2.546$ ), $\mathrm{p}=0.018$ (significant at $5 \%$ level, 95\% CI) (fig 2) 


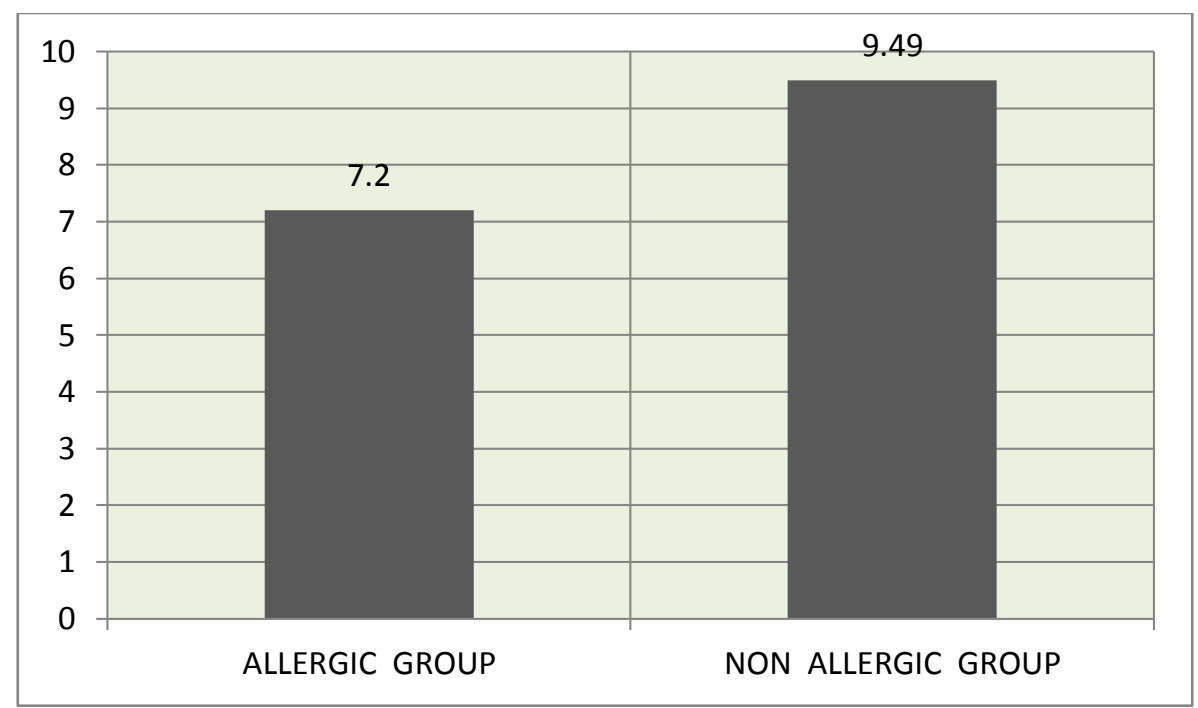

Fig 2:-Mean decrease in NOSE score.

Allergic and non-allergic groups were not found to differ to a statistically significant extent with regard to gender, complaints of nasal bleed, facial pain, presence of external nasal deformity and side of maximum deviation. Among the 83 subjects, about one third was allergic. Allergic and Non-allergic groups were found to differ to a statistically significant extent with regard to age (mean age of allergic group $=27.80 \pm 8.464$, mean age of non-allergic group $=37.44 \pm 8.318, \mathrm{p}$ value $<0.00)$. Incidence of Headache $(\mathrm{p}=0.032)$, Post nasal drip $(\mathrm{p}<0.001)$, Smell disturbance $(\mathrm{p}<0.001)$, Snoring $(\mathrm{p}=0.017)$, Nasal $\operatorname{spur}(\mathrm{p}=0.042)$, Inferior turbinate hypertrophy $(\mathrm{p}=0.009)$ were found to be greater in allergic group to a statistically significant extent. Overall Vestibular, Valvular area (Cottle's area 2,3) or rather anterior septal deviations are common, however allergic and non-allergic groups were not found to differ to a statistically significant extent with regard to the site of septal deviation. Allergic patients had higher incidence pale mucousa when compared to the non-allergic group to a statistically significant extent $(\mathrm{p}=0.009)$, also the incidence of bilateral turbinate hypertrophy was more in the allergic patients. Allergic group had high titers of serum total IgE to a statistically significant extent compared to non-allergic group $(\mathrm{p}<0.001)$.

\section{Conclusion:-}

Based on the prementioned data from subjective measurements, a conclusion with major impact on patient management is reached. Coexistence of allergic rhinitis with nasal septum deviation seems to place patients in a less favourable prognostic group as far as surgical outcome and patient satisfaction are concerned. This conclusion is similar to the usual, undocumented, clinical observation that patients without allergic rhinitis undergoing septoplasty tend to be more satisfied post-operatively. The present study suggests that allergic rhinitis should be strongly considered during patient selection for septoplasty.

\section{Recommendations:-}

1. It becomes clear that the surgeon should proceed with caution when managing patients with both allergic rhinitis and nasal septal deviation.

2. Allergic patients are more likely to be less satisfied after septoplasty compared to patients without allergy.

3. Adequate medical management of allergic rhinitis should be the first priority for these cases.

4. Treatment for allergic rhinitis should be continued following the correction of nasal septal deviation for satisfactory outcome.

5. This study only explains the extent to which the septoplasty outcome is affected by the allergic rhinitis status, in future, a study on the effect of septoplasty on the clinical course of allergic rhinitis will throw more light. 


\section{References:-}

1. Gray LP. Deviated nasal septum. Incidence and etiology. Ann OtolRhinolLaryngol Suppl. 1978 May-Jun; 87(3 Pt 3 Suppl 50):3-20.

2. Jalowayski AA, Yuh YS, Koziol JA, Davidson TM. Surgery for nasal obstruction-evaluation by rhinomanometry. Laryngoscope. 1983 Mar; 93(3):341-5.

3. Stewart MG, Smith TL, Weaver EM, Witsell DL, Yueh B, Hannley MT, Johnson JT. Outcomes after nasal septoplasty: results from the Nasal Obstruction Septoplasty Effectiveness (NOSE) study. Otolaryngol Head Neck Surg. 2004 Mar; 130(3):283-90.

4. ChetanGhorpade, Raghuji D Thorat, VasantiPatil.Efficacy of performing septoplasty in allergic rhinitis. MedPulse- International medical journal. March 2016;3(3):288-291.

5. Demoly P, Jankowski R, Chassany O, Bessah Y, Allaert FA. Validation of a self-questionnaire for assessing the control of allergic rhinitis. Clinical \& Experimental Allergy. 2011 Jun 1;41(6):860-8.

6. Kim YH, Kim BJ, Bang KH, Hwang Y, Jang TY. Septoplasty improves life quality related to allergy in patients with septal deviation and allergic rhinitis. Otolaryngology--Head and Neck Surgery. 2011 Dec 1;145(6):910-4.

7. Bousquet J, Van Cauwenberge P, Khaltaev N. Allergic rhinitis andits impact on asthma (ARIA). J Allergy ClinImmunol, 2001; 108:5174-5334.

8. Kahveci, Orhan Kemal, et al. "The efficiency of Nose Obstruction Symptom Evaluation (NOSE) scale on patients with nasal septal deviation." AurisNasus Larynx 39.3 (2012): 275-279.

9. Cottle M. Concepts of nasal physiology as related to nasal surgery, ArchOtolaryngol. 1960; 72: 11.

10. Johansson SGO, Berglund A, Kjellman NI. Comparison of IgE values as determined by different solid phase radioimmunoassay methods. Clin Allergy 1976; 6:91. 